\title{
Acute and 28-Day Subacute Toxicity Studies of Hexane Extracts of the Roots of Lithospermum erythrorhizon in Sprague-Dawley Rats
}

\author{
Chung-Tack Han', Myoung-Jun Kim', Seol-Hee Moon', Yu-Rim Jeon ', Jae-Sik Hwang', \\ Chunja Nam ${ }^{1}$, Chong-Woo Park ${ }^{1}$, Sun-Ho Lee', Jae-Bum Na ${ }^{1}$, Chan-Sung Park ${ }^{1}$, Hee-Won Park ${ }^{1}$, \\ Jung-Min Lee', Ho-Song Jang ${ }^{1}$, Sun-Hee Park ${ }^{1}$, Kyoung-Goo Han ${ }^{1}$, Young Whan Choi ${ }^{2}$, \\ Hye-Yeong Lee ${ }^{1}$ and Jong-Koo Kang ${ }^{1,3}$ \\ ${ }^{1}$ Biotoxtech Co., Ltd., Cheongju, Korea \\ ${ }^{2}$ Department of Horticultural Bioscience, Pusan National University, Miryang, Korea \\ ${ }^{3}$ Department of Laboratory Animal Medicine, College of Veterinary Medicine, Chungbuk National University, Cheongju, Korea
}

(Received March 13, 2015; Revised May 7, 2015; Accepted July 3, 2015)

\begin{abstract}
Lithospermum erythrorhizon has long been used as a traditional oriental medicine. In this study, the acute and 28-day subacute oral dose toxicity studies of hexane extracts of the roots of L. erythrorhizon (LEH) were performed in Sprague-Dawley rats. In the acute toxicity study, LEH was administered once orally to 5 male and 5 female rats at dose levels of $500,1,000$, and 2,000 mg/ $/ \mathrm{kg}$. Mortality, clinical signs, and body weight changes were monitored for 14 days. Salivation, soft stool, soiled perineal region, compound-colored stool, chromaturia and a decrease in body weight were observed in the extract-treated groups, and no deaths occurred during the study. Therefore, the approximate lethal dose (ALD) of LEH in male and female rats was higher than $2,000 \mathrm{mg} / \mathrm{kg}$. In the subacute toxicity study, LEH was administered orally to male and female rats for 28 days at dose levels of 25,100 , and $400 \mathrm{mg} / \mathrm{kg} / \mathrm{day}$. There was no LEH-related toxic effect in the body weight, food consumption, ophthalmology, hematology, clinical chemistry and organ weights. Compound-colored (black) stool, chromaturia and increased protein, ketone bodies, bilirubin and occult blood in urine were observed in the male and female rats treated with the test substance. In addition, the necropsy revealed dark red discoloration of the kidneys, and the histopathological examination showed presence of red brown pigment or increased hyaline droplets in the renal tubules of the renal cortex. However, there were no test substance-related toxic effects in the hematology and clinical chemistry, and no morphological changes were observed in the histopathological examination of the kidneys. Therefore, it was determined that there was no significant toxicity because the changes observed were caused by the intrinsic color of the test substance. These results suggest that the no-observed-adverseeffect Level (NOAEL) of LEH is greater than $400 \mathrm{mg} / \mathrm{kg} /$ day in both sexes.
\end{abstract}

Key words: Lithospermum erythrorhizon, Shikonin derivatives, Acute oral toxicity, 28-Day subacute oral toxicity

\section{Correspondence to: Hye-Yeong Lee, Biotoxtech Co., Ltd., 53, Yeo- ngudanji-ro, Ochang-eup, Cheongwon-gu, Cheongju-si, Chungbuk 363-883, Korea \\ E-mail: hylee@biotoxtech.com \\ Jong-Koo Kang, Department of Laboratory Animal Medicine, Col- lege of Veterinary Medicine, Chungbuk National University, 1 Chungdae-ro, Seowon-gu, Cheongju, Chungbuk 361-763, Korea E-mail: jkkang@cbu.ac.kr}

This is an Open-Access article distributed under the terms of the Creative Commons Attribution Non-Commercial License (http:// creativecommons.org/licenses/by-nc/3.0) which permits unrestricted non-commercial use, distribution, and reproduction in any medium, provided the original work is properly cited.

\section{INTRODUCTION}

Advances in medical technology have encouraged studies examining the development and novel use of biological resources locally and internationally. A number of natural substances are currently widely used as raw materials for medicine, health functional foods and home remedies $(1,2)$.

Natural products are believed to be safer than chemical products. Therefore, toxicity studies of natural substances do not usually receive as much attention as studies of chemical products. However, some natural substances are 
potentially toxic and may be harmful to human health (35). In addition, issues regarding the actual safety of natural substances are constantly discussed (3-5). Therefore, systematic safety studies are also essential for compounds that are natural-based medicines or functional health foods.

The extracts of the roots of jichi (Lithospermum erythrorhizon Siebold and Zucc, LE) have naphthoquinone pigments containing shikonin and shikonin derivatives. These extracts have been used in the Orient for many centuries as natural red dyes and crude drugs for the treatment of burns, chicken pox, carbuncles, measles, macular eruptions and sore throat (6-8).

LE has been reported to have various pharmacological actions including potent anti-inflammatory (9-11), anti-cancer $(12,13)$, anti-human immunodeficiency virus (HIV) (14), anti-oxidant, immunomodulatory (15-17), anti-atopic dermatitis (18), anti-allergic (19), skin protectant against ultraviolet (UV) B rays (20-22), antibacterial (23), woundhealing (24) and antimicrobial (25) properties. There are few studies evaluating the safety of LE while numerous studies have examined its pharmacological actions and value in preclinical use.

In this study, the single oral dose toxicity and 28-day subacute oral dose toxicity studies with a 14-day recovery period followed by qualitative and quantitative examinations were conducted with the hexane extracts of LE (LEH) in Sprague-Dawley rats. These studies aimed at acquiring safety data for the application of a natural substance based medicine, including information about the NOAEL and target organs.

\section{MATERIAL AND METHODS}

Test substance. The test substance, LEH, was supplied by the Department of Horticultural Bioscience, Pusan National University (Miryang 627-706, Republic of Korea). The dried roots of LE were ground into a fine powder and then, successively extracted 3 times with $n$-hexane in a sonicator at room temperature. The suspension was filtered, evaporated under reduced pressure at low temperature, and then lyophilized. The hexane extract was obtained as a red oily residue designated as $\mathrm{LEH}$, and contained different types of naphthoquinones in abundance. An Agilent/HP 1100 series HPLC-DAD system consisting of a vacuum degasser, binary pump, autosampler, thermostated column compartment and DAD (Agilent, Palo Alto, CA, USA) was used for quantitative analysis and UV spectral acquisition. The major components of the LEH include 3 shikonin derivatives: acetylshikonin, isobutylshikonin, and $\beta$-hydroxyisovalerylshikonin at concentrations of 23.24, 18.62 and $15.07 \%$, respectively. This LEH (hexane extract) showed in vitro and in vivo anticancer effects on B16F10 murine melanoma (26).
Experimental animals and husbandry. In this study, the specific pathogen-free (SPF) Crl:CD Sprague-Dawley (SD) rats (5-week old) used in the acute and subacute toxicity studies were obtained from Orient Bio Inc., (Seongnam$\mathrm{Si}$, Gyeonggi-do, Korea). During the study period, the animals were housed in a room maintained at a temperature of $22 \pm 3{ }^{\circ} \mathrm{C}$ and relative humidity of $50 \pm 20 \%$, with artificial lighting from 07:00 to 19:00 at 150 to 300 Lux of luminous intensity and 10 to 15 air changes per hour. The animals were acclimatized to laboratory conditions for 7 days prior to commencement of the experiments. No more than 3 animals were housed in a stainless steel wire mesh cage $(260 \times$ $350 \times 210 \mathrm{~mm}$ ) during the quarantine and acclimation, and 1 animal per cage during the dosing periods. A label with the study number and animal ID distinguished each cage.

Animals were allowed irradiation-sterilized pellet feed (Teklad certified irradiated global $18 \%$ protein rodent diet, 2918C, Harlan Co., Hayward, CA, USA) and disinfected groundwater by an ultraviolet sterilizer and ultrafiltration, ad libitum.

Preparation of dose formulations. The required amount of the test extract was weighed using an electronic balance (Sartorius, Germany) and placed in a bottle. A small amount of the vehicle saline was added and mixed by vortexing until the extract dissolved. The desired concentrations were obtained by gradually adding more vehicle.

The concentrations of the various extract dosing formulations were verified using high-performance liquid chromatography (HPLC, Agilent 1100 Series, Agilent Technologies Ltd., USA).

Homogeneity and stability analyses were conducted by Biotoxtech Co., Ltd. for the study of "An Analytical Method Validation, Stability Study of Lithospermum erythrorhizon extracts Dosing Formulations (Biotoxtech Study No.: B12610)". Dosing formulations remained homogeneous and stable for $4 \mathrm{hrs}$ at room temperature and for 7 days when refrigerated. After that, each dosing formulation was periodically prepared at least twice a week and refrigerated $\left(4.1 \sim 6.9^{\circ} \mathrm{C}\right)$.

Triplicate samples were collected from the mid-layer of each dosing formulation and analyzed prior to the first dosing. The accuracies of the 25,100 , and $400 \mathrm{mg} / \mathrm{kg} /$ day dosing formulations of LEH were 99.26, 99.38, and 90.83\%, respectively prior to the first dosing. These results were within the acceptable range (range $\pm 15 \%$ of nominal values).

Study design overview. The present study was conducted at the Good Laboratory Practice (GLP) Institute and approved by the Ministry of Food and Drug Safety (MFDS). The study complied with the GLP and test guidelines of the Organization for Economic Cooperation and Development (OECD) and the MFDS. 
This study was also reviewed and approved by the Institutional Animal Care and Use Committee (IACUC) of Biotoxtech Co., Ltd. based on the Animal Protection Act (Enactment May 31, 1991, No. 4379; Revision August 4, 2011, No. 120779).

Extract administration. The oral route was selected for the administration of LEH directly into the stomach, via a gavage needle. In the acute toxicity study, animals were fasted overnight for approximately $16 \mathrm{hrs}$ prior to dosing. Drinking water was provided ad libitum and the feed, approximately $4 \mathrm{hrs}$ after dosing. In the subacute toxicity study, LEH was orally administered once a day for 28 days without fasting. The dosing volume was $5 \mathrm{~mL} / \mathrm{kg} /$ day based on the most recently measured body weights in the single and repeated dose toxicity studies.

Acute oral dose toxicity study. A total of 5 male and 5 female rats (6-week old) per group were orally administered LEH at doses of 0 (corn oil, vehicle control), 500, 1000 and $2000 \mathrm{mg} / \mathrm{kg}$. All animals were observed for clinical signs and mortality (time of toxic symptom onset and recovery, etc.) at $30 \mathrm{~min}, 1,2,4$, and $6 \mathrm{hrs}$ after dosing and twice a day thereafter for the 14-day experimental period.

The body weights were recorded prior to dosing and on days 1, 3, 7, and 14 after dosing using an electronic balance (Sartorious Co., Germany). On day 14 of dosing, all the animals were anesthetized with an overdose of $\mathrm{CO}_{2}$ gas, exsanguinated via the abdominal aorta, and complete gross postmortem examinations were performed.

\section{Subacute oral toxicity study.}

Dose Levels group designation: The dose levels were selected based on the result of a preliminary 2-week repeated oral dose range finding toxicity study (Biotoxtech Study No.: B12612). The high dose level was set at $400 \mathrm{mg} /$ $\mathrm{kg} /$ day, at which toxicity was expected in this study. The medium and high doses were set at 100 and $25 \mathrm{mg} / \mathrm{kg} /$ day, respectively, by applying a geometric ratio of $1 / 4$. Control animals received vehicle only (corn oil). A total of 10 male and 10 female rats (6-week-old) per group were administered LEH at doses of 0 (corn oil, vehicle control), 25, 100, and $400 \mathrm{mg} / \mathrm{kg} / \mathrm{day}$. Additional animals, 5 for each sex, were added to the control and the high dose groups for the recovery study.

Clinical signs and mortality: All the animals were observed once daily for clinical signs and twice daily for mortality and morbidity throughout the study. The animals in the main groups were observed for 4 weeks, and those of the recovery groups were observed for 2 weeks after final dosing.

Body weights: Body weights were recorded prior to dosing on day 1 , once a week during the dosing and recovery periods, and on the day of necropsy. However, body weights measured on the necropsy day were not analyzed statistically since these data were taken while all animals were fasted. Body weights of the recovery group animals were recorded on the next day of the final dosing.

Food consumption: The food consumption was measured daily from the day of group assignment to the day of dosing initiation. During the dosing and recovery periods, the mean daily food consumption was calculated from the total amount consumed in 7 days. However, it was calculated for 6 days at week 4 and recovery week 2 .

Ophthalmological examinations: Ophthalmic examinations were conducted for both eyes of 5 animals per sex for each main group and all animals in the recovery group at weeks 4 and 2, respectively. A mydriatic agent (Lot No.: 023421, OcuTropine ophthalmic drops, Samil Co., Ltd., Korea) was instilled into the eyes of the rats prior to the examinations. The anterior segment, transparent media, and ocular fundus of the eye were observed using an ophthalmoscope (All Pupil II, Keeler, UK).

Urinalysis: The urinalysis was conducted on 5 animals of each sex in the main groups at week 4 and all animals in the recovery groups at recovery week 2 . Fresh urine (within $3 \mathrm{hrs}$ after excretion) and cumulative urine (over a period of approximately $24 \mathrm{hrs}$ ) samples were collected. During the collection of the fresh urine samples, the animals were not dosed or given food, but drinking water was provided ad libitum. The parameters for the urinalysis included volume, color and turbidity, sediment, specific gravity, $\mathrm{pH}$, protein, glucose, ketone bodies, occult blood and bilirubin (Combur ${ }^{10}$ Test $^{\mathbb{R}} \mathrm{M}$ stick, Roche, Germany), and chemistry (Miditron ${ }^{\circledR}$ Junior II urine analyzer, Roche, Germany).

Hematology: Prior to necropsy, all animals were fasted overnight for approximately $18 \mathrm{hrs}$. The animals were anesthetized with isoflurane (Ifran liquid, Hana Pharm, Co., Ltd., Korea) and blood samples of approximately $1 \mathrm{~mL}$ were collected from the abdominal aorta. The blood was placed in evacuated tubes containing $\mathrm{K}_{2}$-EDTA as anticoagulant $\left(\mathrm{BD}^{\mathrm{TM}}\right.$ Vacutainer,. Becton Dickinson, Franklin Lakes, New Jersey, USA) and used for the hematological and serum biochemical tests. The following hematological parameters were evaluated using a Coulter counter (Advia 120, Siemens, Germany): red blood cell (RBC) count, hemoglobin (HGB), hematocrit (HCT), mean corpuscular volume (MCV), mean corpuscular hemoglobin $(\mathrm{MCH})$, mean corpuscular hemoglobin concentration (MCHC), reticulocytes (Reti), platelet (PLT) count, white blood cell (WBC) count, and WBC differential count, which includes neutrophils (NEU), lymphocytes (LYM), monocytes (MONO), eosinophils (EOS), and basophils (BASO). Next, $2 \mathrm{~mL}$ of blood was dispensed into microtubes containing $0.2 \mathrm{~mL}$ of $3.2 \%$ sodium $(\mathrm{Na})$ citrate, and plasma was obtained by centrifugation (3,000 rpm, Union 32R plus, Hanil Science Industrial, Incheon, Korea) for $10 \mathrm{~min}$. The plasma prothrombin time (PT) and activated partial thromboplastin 
time (APTT) were measured in seconds using the coagulation time method with a coagulation time analyzer (Coapresta 2000, Sekisui, Japan).

Serum biochemistry: The remaining blood samples collected for the hematological examination were centrifuged (3,000 rpm, Union 32R plus, Hanil Science Industrial, Incheon, Korea) for $10 \mathrm{~min}$ to obtain the serum. The following parameters were then analyzed using an automatic analyzer (7180, Hitachi, Japan) and electrolyte analyzer (AVL9181, Roche, Germany): alanine aminotransferase (ALT), aspartate aminotransferase (AST), alkaline phosphatase (ALP), gamma glutamyl transpeptidase (GGT), total bilirubin (Tbil), glucose (Glu), total cholesterol (TChol), triglyceride (TG), total protein (TP), albumin (Alb), albumin/ globulin $(\mathrm{A} / \mathrm{G})$ ratio, blood urea nitrogen $(\mathrm{BUN})$, creatinine (Crea), inorganic phosphorus (IP), and calcium (Ca). The electrolytes including $\mathrm{Na}^{+}$, potassium ion $\left(\mathrm{K}^{+}\right)$, and chloride ion $\left(\mathrm{Cl}^{-}\right)$were also determined.

Gross findings: Complete gross postmortem examinations of the external and internal surfaces were performed on all animals, and all grossly visible abnormalities were recorded.

Organ weights: The following organs were weighed using an electronic balance (Sartorius, Germany), and paired organs were weighed together: brain, heart, pituitary gland, lungs, spleen, liver, kidneys, adrenal glands, testis, prostate gland, ovaries, and uterus. The weights were converted to relative organ weights based on the organ-tofasted body weight ratio.

Histopathological examination: The following organs and tissues were fixed in $10 \%$ neutral-buffered formalin except for the testes and eyes, which were fixed in Davidson's fixative: brain, pituitary, thyroid, parathyroid, thymus, lungs (including the bronchi), trachea, heart, liver, spleen, kidneys, adrenal glands, salivary gland (submandibular, sublingual, and parotid glands), tongue, esophagus, stomach, duodenum, jejunum, ileum, cecum, colon, rectum, pancreas, testes, epididymides, prostate, seminal vesicle, ovaries, uterus, vagina, urinary bladder, submandibular lymph node, mesenteric lymph node, eyes (including the optic nerve and Harderian glands), mammary gland, skin, sternum (including bone marrow), femur (including bone marrow), and thoracic spinal cord.

Microscopic examinations were performed on all the tissues from the animals of the control and high-dose groups and test substance-related findings noted at the high-dose were examined in the mid- and low-dose groups (kidneys and stomach). The preserved organs and tissues were trimmed, dehydrated, embedded in paraffin, sectioned, and stained with hematoxylin and eosin (H\&E) stain and the kidneys were treated with chromotrope-aniline blue (CAB) stain for microscopic examination. The bones were decalcified with Calci-Clear-Rapid ${ }^{\mathrm{TM}}$ (National Diagnostics, USA) before trimming. All the remaining organs and tissues were preserved in $10 \%$ neutral buffered formalin.

Statistical analysis. The statistical analyses were performed using the statistical analysis software (SAS) program (version 9.3, SAS Institute Inc., USA) for quantitative data including the body weight, food consumption, urine volume, hematology, clinical chemistry, and organ weight.

The results were expressed as means \pm standard deviation (SD). In the acute toxicity and repeated oral dose toxicity study (main group), the Bartlett's test was performed to test the homogeneity of variance (significance level, 0.05 ). When the variances of all populations were assumed equal, a one-way analysis of variance (ANOVA) was conducted. Here, the significance was further tested using the Dunnett's test for multiple comparisons (significance levels, 0.05 and 0.01 , two-tailed). When the variances were heterogeneous, the Kruskal-Wallis test was conducted. Here, the significance was further tested using the Steel test for nonparametric multiple comparisons (significance levels, 0.05 and 0.01 , two-tailed).

In the recovery groups of the repeated oral dose toxicity study, the data were analyzed using the F-test for homogeneity of variance (significance level, 0.05 ). When the variances of two populations were assumed homogeneous, the Student- $t$ test was conducted (significance levels, 0.05 and 0.01 , two-railed). When the variances were heterogeneous, the Aspin-Welch test was performed (significance levels, 0.05 and 0.01 , two-tailed).

\section{RESULTS AND DISCUSION}

\section{Acute oral toxicity study.}

Clinical signs and mortality: No mortality was observed during the study period. The clinical signs including soft stool, mucoid stool, salivation, diarrhea, and soiled perineal region were mainly observed in male and female rats in the $500,1,000$, and $2,000 \mathrm{mg} / \mathrm{kg}$ treated groups, from the day of administration to day 2 of dosing. In addition, the occurrence of compound-colored stool was dose-related in 1 to 5 cases from day 1 to 6 . Furthermore, in the rats treated with LEH at 1,000 and $2,000 \mathrm{mg} / \mathrm{kg}$, the chromaturia was sporadically observed in 1 to 5 cases on days 2 and 3 of the dosing period. Mucoid stool was observed in 2 female rats in the control group on the day of administration. The clinical signs such as salivation, soft stool, soiled perineal region, diarrhea, compound-colored stool, and chromaturia observed in the rats treated with LEH were thought to be extract- and dose-related changes since they were not observed in the control group. The mucoid stool was observed sporadically at low frequency in male and female rats in the LEH-treated groups on the day of administration. This sign was also observed in female rats in the vehicle control group and, therefore, it was considered to be caused by the effect of the vehicle (corn oil) rather than LEH. 

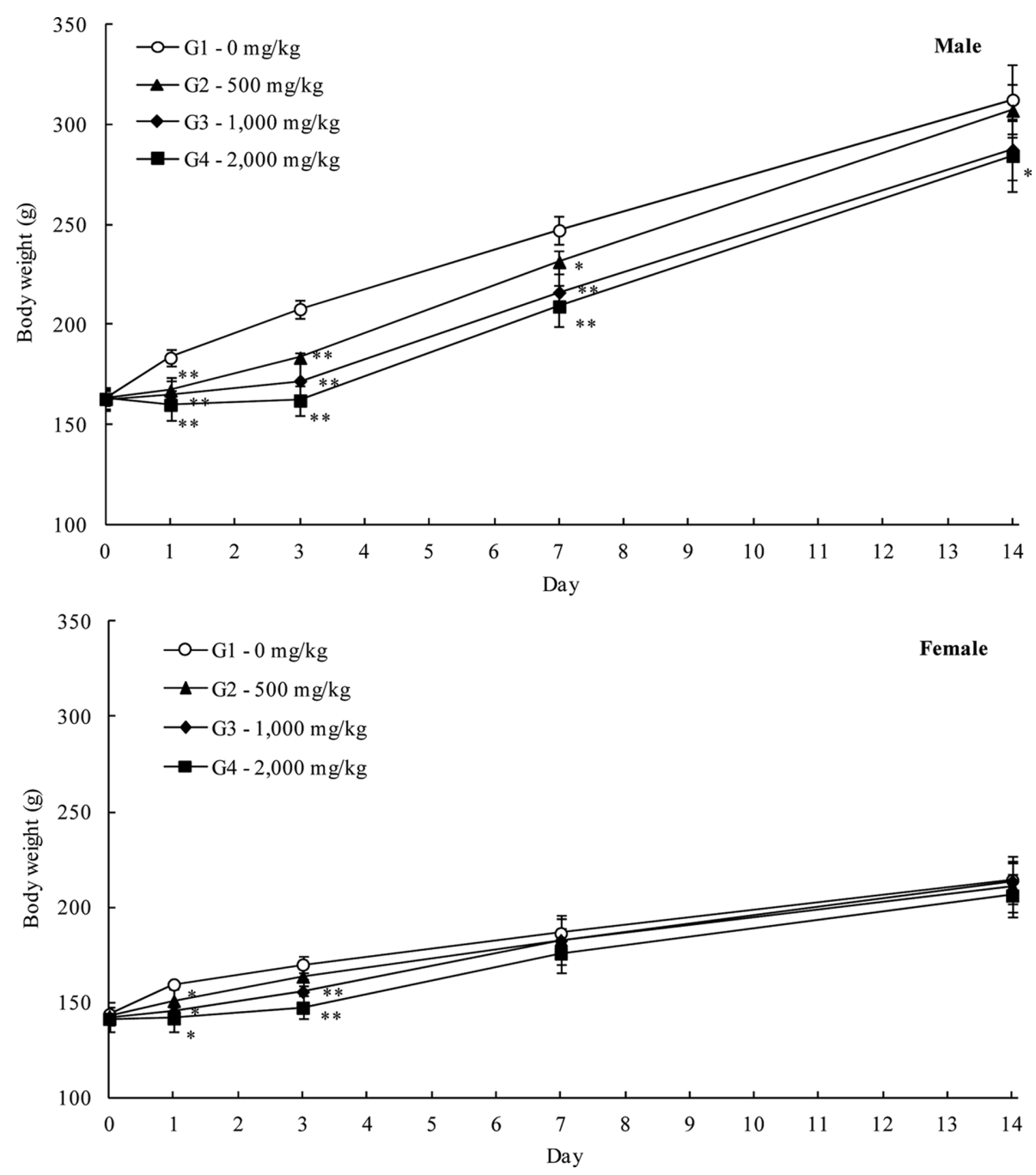

Fig. 1. Mean body weight (Mean \pm S.D) of male and female rats in the acute oral dose toxicity study of the LEH. Significantly different from vehicle control: ${ }^{*} p<0.05,{ }^{* *} p<0.01$, respectively.

Body weights: The body weight measurements showed suppressed weight gain in the LEH-treated rats (Fig. 1). Statistically significantly lower body weights were evident in male rats in the $500,1,000$, and $2,000 \mathrm{mg} / \mathrm{kg}$ groups on Days 1, 3, and 7 and in the $2,000 \mathrm{mg} / \mathrm{kg}$ group on Day 14 after dosing ( -6.4 to $-22.0 \%, p<0.05$ or $p<0.01$ ), and in female rats in the $500,1,000$, and $2,000 \mathrm{mg} / \mathrm{kg}$ groups on Day 1 and in the $2,000 \mathrm{mg} / \mathrm{kg}$ group on Day 3 after dosing $(-5.4$ to $-13.3 \%, p<0.05$ or $p<0.01)$ when compared to the control groups. These differences were sex- and doserelated changes and considered to be LEH-related.

Gross findings: The necropsy showed no abnormal findings in the male and female control groups and the 500, 1,000 , and 2,000 $\mathrm{mg} / \mathrm{kg}$ extract-treated rat groups.

\section{Subacute oral toxicity study.}

Clinical signs and mortality: During the LEH administration, one male rat died on day 3 in the $25 \mathrm{mg} / \mathrm{kg} /$ day extract-treated group, and no abnormal clinical signs were observed prior to death. The results of necropsy revealed a discoloration in the lung, which was observed in the left lobe and right caudal lobe. In addition, there was also pneumonitis of the left lobe, and congestion of the right caudal lobe was discovered in the histopathological examination. These findings were not observed in the high-dose group, and the death was deemed accidental and unrelated to the administration of LEH.

The subacute toxicity study revealed a continuous production of compound-colored (black) stool at high-frequency in the male and female rats treated with LEH during the administration, as well as the early recovery period. Chromaturia of a pale brown color was observed in the male and female rats in the $400 \mathrm{mg} / \mathrm{kg}$ /day LEH-treated groups during the administration period but not in the normal control group. These observed changes were considered to be caused by the physical property (color) of the 


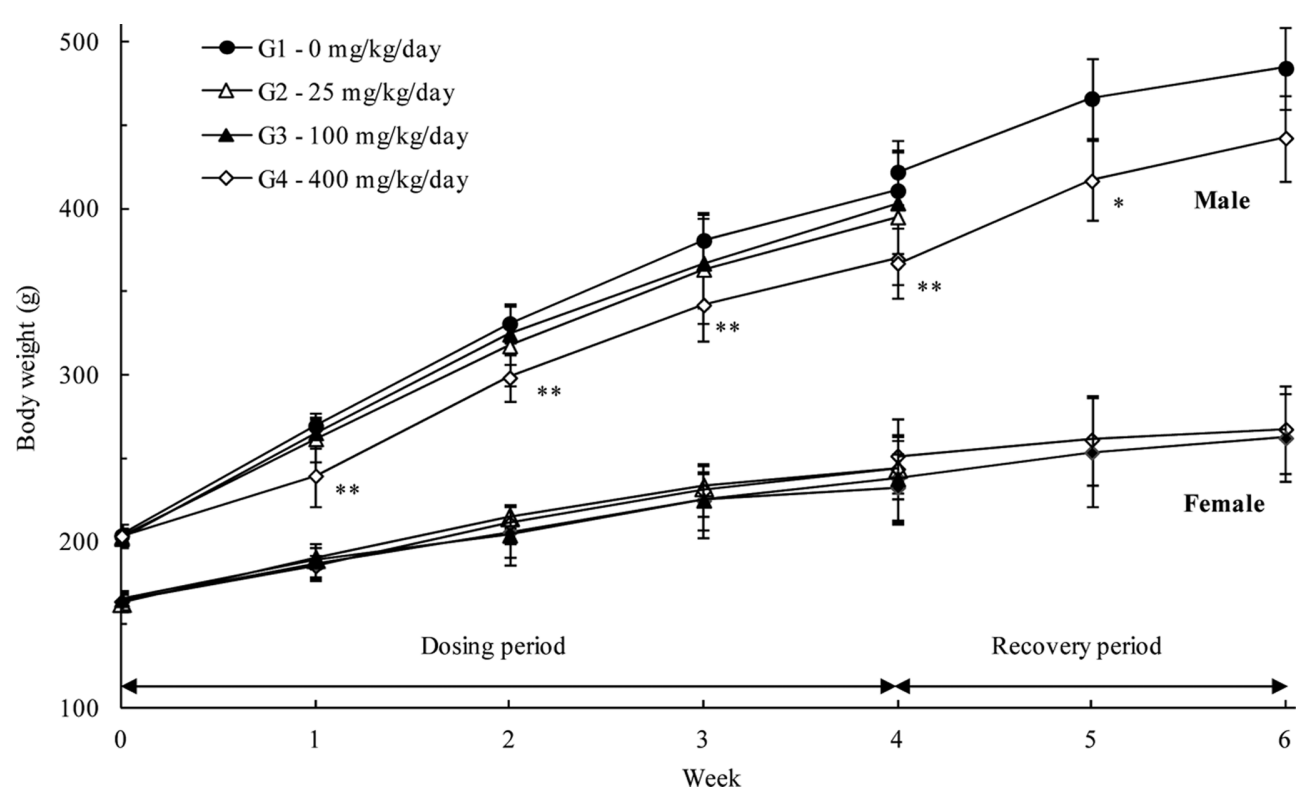

Fig. 2. Mean body weight (Mean \pm S.D) of male and female rats in the 28 day repeated oral dose toxicity study of the LEH with 14 day recovery period. Significantly different from vehicle control: ${ }^{*} p<0.05,{ }^{* *} p<0.01$, respectively.

LEH and we concluded that this had no toxicological significance. Salivation was observed temporarily and at a low frequency before and after the administration of the LEH, and it was not observed during the recovery period. Therefore, we concluded that the salivation had no toxicological significance.

Body weights: The body weight measurements showed a tendency towards suppression of weight gain in male rats treated with $400 \mathrm{mg} / \mathrm{kg} /$ day LEH during the administration and recovery periods. The body weights recorded during week $4(369.8 \pm 23.1 \mathrm{~g})$ and recovery week $2(442.4 \pm 26.0$ g) decreased by about 9.98 and $8.65 \%$, respectively (Fig. 2). However, the change was less than $10 \%$, and no significant changes related to the administration of LEH were observed in female rats. Therefore, the change was not considered toxicologically significant.

Food consumption: The food consumption measurements showed that male rats treated with $25 \mathrm{mg} / \mathrm{kg} /$ day at weeks 2 and 3, and rats in the $400 \mathrm{mg} / \mathrm{kg} /$ day treated groups at week 1 consumed significantly lower amounts of feed than the control group. However, it was a temporary change that did not correlate with the dose or sex. During the recovery period, there was no significant change in the food consumption in the rats treated at $400 \mathrm{mg} / \mathrm{kg} / \mathrm{day}$ compared to that of the control group (data not shown).

Ophthalmologic examination: The ophthalmoscopic examination showed no abnormalities in both the main study group and recovery group (data not shown).

Urinalysis: The results of the urinalysis revealed a change in the urine color (grayish-pale yellow, amber or brown) while increased urinary protein, ketone bodies, bili- rubin, and occult blood were observed in the LEH-treated groups (Table 1). These findings were mainly associated with the change in the urine color caused by LEH. Therefore, they were not considered toxicologically significant.

Hematology: Results of the hematological parameters are shown in Table 2. The HGB $(p<0.01)$ and HCT $(p<$ $0.05)$ were significantly lower in the female rats in the $400 \mathrm{mg} / \mathrm{kg} /$ day LEH-treated group of the main study than those in the control group. In the recovery group, the MCHC was significantly lower in the male rats in the $400 \mathrm{mg} / \mathrm{kg} /$ day LEH-treated group than in those in the control group $(p<0.05)$. These changes were not considered toxicologically significant because they were relatively minor and within the acceptable ranges (27), and were not consistent.

Serum biochemistry: Results of the serum biochemical parameters are shown in Table 3. In the main study group, the levels of IP in the rats in the 100 and $400 \mathrm{mg} / \mathrm{kg} /$ day LEH-treated groups were higher than those in the control group $(p<0.05$ or $p<0.01)$. This effect was a relatively high dose- and sex-related change and considered to be related to LEH. However, toxicologically significant changes were not observed in the other parameters in relation to the IP, and the recovery groups showed results that were similar to the control group. Therefore, this effect was not considered toxicologically significant under the condition of this study.

Other statistically significant changes observed in the main study and recovery groups did not show any larger differences than were observed in the control group. These changes were not dose-related or consistent and, therefore, 
Table 1. Urinalysis of male and female rats

\begin{tabular}{|c|c|c|c|c|c|c|c|c|c|c|c|c|c|}
\hline \multirow{3}{*}{ Parameters } & \multirow{3}{*}{ Result } & \multicolumn{6}{|c|}{ Male } & \multicolumn{6}{|c|}{ Female } \\
\hline & & \multicolumn{4}{|c|}{$\begin{array}{l}\text { Main group } \\
(\mathrm{mg} / \mathrm{kg} / \text { day })\end{array}$} & \multicolumn{2}{|c|}{$\begin{array}{l}\text { Recovery group } \\
(\mathrm{mg} / \mathrm{kg} / \text { day })\end{array}$} & \multicolumn{4}{|c|}{$\begin{array}{l}\text { Main group } \\
\text { (mg/kg/day) }\end{array}$} & \multicolumn{2}{|c|}{$\begin{array}{c}\text { Recovery group } \\
\text { (mg/kg/day) }\end{array}$} \\
\hline & & 0 & 25 & 100 & 400 & 0 & 400 & 0 & 25 & 100 & 400 & 0 & 400 \\
\hline \multirow[t]{2}{*}{ Volume (mL) } & Mean & 7.6 & 4.7 & 6.1 & 11.7 & 9.5 & 8.8 & 5.4 & 4.7 & 3.7 & 5.1 & 5.4 & 10.6 \\
\hline & S.D. & 1.9 & 2.2 & 1.5 & 9.0 & 5.0 & 2.5 & 3.4 & 2.1 & 1.9 & 3.9 & 2.7 & 5.0 \\
\hline \multirow[t]{6}{*}{ Color } & Pale yellow & & & & & 3 & & & & & & 2 & 1 \\
\hline & Yellow & 5 & 5 & 1 & & 2 & 5 & 5 & 5 & 5 & & 3 & 4 \\
\hline & Yellow light & & & & & & & & & & 3 & & \\
\hline & Yellow light grayish & & & 3 & & & & & & & 1 & & \\
\hline & Amber & & & 1 & 2 & & & & & & & & \\
\hline & Brown & & & & 3 & & & & & & 1 & & \\
\hline Transparency & Clear & 5 & 5 & 5 & 5 & 5 & 5 & 5 & 5 & 5 & 5 & 5 & 5 \\
\hline \multirow[t]{5}{*}{$\mathrm{pH}$} & 6 & 2 & 1 & 2 & & & & & 2 & 3 & & 1 & \\
\hline & 6.5 & & 2 & 1 & 4 & & & & & 2 & 2 & & \\
\hline & 7 & 2 & & 1 & & 1 & 1 & 1 & 1 & & 1 & & 2 \\
\hline & 8 & 1 & & 1 & 1 & 1 & 2 & 1 & & & 1 & 2 & 3 \\
\hline & 9 & & 2 & & & 3 & 2 & 3 & 2 & & 1 & 2 & \\
\hline \multirow[t]{3}{*}{ Protein $(\mathrm{mg} / \mathrm{dL})$} & - & 1 & & & & 3 & 1 & 5 & 3 & 2 & & 3 & 4 \\
\hline & 25 & 4 & 2 & 4 & 1 & 2 & 4 & & 2 & 3 & 4 & 2 & 1 \\
\hline & 75 & & 3 & 1 & 4 & & & & & & 1 & & \\
\hline Glucose (mg/dL) & Normal & 5 & 5 & 5 & 5 & 5 & 5 & 5 & 5 & 5 & 5 & 5 & 5 \\
\hline \multirow[t]{3}{*}{ Ketone body (mg/dL) } & - & 5 & 2 & 3 & 1 & 5 & 5 & 5 & 5 & 4 & 3 & 5 & 5 \\
\hline & 5 & & 1 & 1 & 2 & & & & & 1 & 2 & & \\
\hline & 15 & & 2 & 1 & 2 & & & & & & & & \\
\hline \multirow[t]{2}{*}{ Bilirubin (mg/dL) } & - & 5 & 3 & 4 & 1 & 5 & 5 & 5 & 5 & 5 & 4 & 5 & 5 \\
\hline & 1 & & 2 & 1 & 4 & & & & & & 1 & & \\
\hline \multirow[t]{3}{*}{ Occult blood $($ Ery $/ \mu \mathrm{L})$} & - & 5 & 4 & 4 & & 5 & 4 & 5 & 5 & 4 & 2 & 5 & 5 \\
\hline & 10 & & 1 & 1 & 3 & & 1 & & & 1 & 2 & & \\
\hline & 25 & & & & 2 & & & & & & 1 & & \\
\hline Cast $^{\dagger}$ & 0 & 5 & 5 & 5 & 5 & 5 & 5 & 5 & 5 & 5 & 5 & 5 & 5 \\
\hline Epithelial cell ${ }^{\dagger}$ & 0 & 5 & 5 & 5 & 5 & 5 & 5 & 5 & 5 & 5 & 5 & 5 & 5 \\
\hline Leukocyte ${ }^{\dagger}$ & 0 & 5 & 5 & 5 & 5 & 5 & 5 & 5 & 5 & 5 & 5 & 5 & 5 \\
\hline Erythrocyte $^{\dagger}$ & 0 & 5 & 5 & 5 & 5 & 5 & 5 & 5 & 5 & 5 & 5 & 5 & 5 \\
\hline \multirow[t]{6}{*}{ Specific gravity } & $1.011 \sim 1.020$ & & & & 2 & & & & & & & & \\
\hline & $1.021 \sim 1.030$ & & & & & & & & & & & 2 & \\
\hline & $1.031 \sim 1.040$ & & & 2 & & 1 & & 4 & 1 & & 1 & & 2 \\
\hline & $1.041 \sim 1.050$ & 1 & & 1 & 2 & 1 & 1 & 1 & 2 & 2 & 1 & 2 & 2 \\
\hline & $1.051 \sim 1.060$ & 3 & 2 & 2 & & 2 & 3 & & & 1 & & & \\
\hline & $>1.060$ & 1 & 3 & & 1 & 1 & 1 & & 2 & 2 & 3 & 1 & 1 \\
\hline No. of animals & & 5 & 5 & 5 & 5 & 5 & 5 & 5 & 5 & 5 & 5 & 5 & 5 \\
\hline
\end{tabular}

${ }^{\dagger}$ : Sediment.

they were not considered toxicologically significant.

Gross findings: The results of the necropsy revealed dark-red discoloration of the kidneys in all animals in the $400 \mathrm{mg} / \mathrm{kg} /$ day LEH-treated groups of the main study and recovery groups. This change was dose-related and considered to be related to LEH. In addition, the presence of a redbrown pigmentation in the renal tubules was observed in the histopathological examination.

Organ weights: The results of organ weight measurements are shown in Table 4. The results of the organ weight measurement showed significant increases in the absolute and relative weights of the liver of the female rats in the $400 \mathrm{mg} / \mathrm{kg}$ /day LEH-treated main study group. In addition, the relative weight of the liver of the male rats in this group was higher than that of the control group. These weight changes were dose-related and considered LEH-related. However, no changes in the parameters related to liver toxicity were observed in the hematological and serum biochemical examinations. In addition, morphological changes of the organs were not found during the histopathological examination and no abnormal changes were observed in the recovery groups. Therefore, the aforementioned changes 
Table 2. Hematological values of male and female rats

\begin{tabular}{|c|c|c|c|c|c|c|}
\hline \multirow{2}{*}{ Items } & \multicolumn{4}{|c|}{ Main group (mg/kg/day) } & \multicolumn{2}{|c|}{ Recovery group (mg/kg/day) } \\
\hline & 0 & 25 & 100 & 400 & 0 & 400 \\
\hline \multicolumn{7}{|l|}{ Male } \\
\hline $\operatorname{RBC}\left(10^{6} / \mu \mathrm{L}\right)$ & $7.63 \pm 0.22$ & $7.64 \pm 0.11$ & $7.55 \pm 0.35$ & $7.55 \pm 0.31$ & $7.99 \pm 0.17$ & $7.98 \pm 0.09$ \\
\hline Hemoglobin (g/dL) & $15.5 \pm 0.7$ & $15.6 \pm 0.8$ & $15.3 \pm 0.8$ & $15.0 \pm 0.6$ & $14.8 \pm 0.3$ & $14.6 \pm 0.4$ \\
\hline Hematocrit $(\%)$ & $44.5 \pm 1.7$ & $44.9 \pm 1.6$ & $43.6 \pm 2.0$ & $43.1 \pm 1.5$ & $43.8 \pm 0.3$ & $44.4 \pm 1.0$ \\
\hline $\mathrm{MCV}(\mathrm{fL})$ & $58.4 \pm 1.8$ & $58.8 \pm 1.8$ & $57.7 \pm 2.0$ & $57.1 \pm 1.3$ & $54.8 \pm 1.3$ & $55.7 \pm 1.5$ \\
\hline $\mathrm{MCH}(\mathrm{pg})$ & $20.3 \pm 0.9$ & $20.5 \pm 0.9$ & $20.2 \pm 1.0$ & $20.0 \pm 0.6$ & $18.5 \pm 0.5$ & $18.3 \pm 0.5$ \\
\hline $\mathrm{MCHC}(\mathrm{g} / \mu \mathrm{L})$ & $34.7 \pm 1.0$ & $34.8 \pm 0.6$ & $35.0 \pm 0.8$ & $34.9 \pm 0.5$ & $33.7 \pm 0.6$ & $32.9 \pm 0.2^{*}$ \\
\hline Platelet $\left(10^{3} / \mu \mathrm{L}\right)$ & $1125 \pm 102$ & $1108 \pm 86$ & $1073 \pm 114$ & $1076 \pm 69$ & $1166 \pm 147$ & $1181 \pm 162$ \\
\hline Reticulocyte (\%) & $2.4 \pm 0.5$ & $2.5 \pm 0.4$ & $2.5 \pm 0.4$ & $2.3 \pm 0.5$ & $2.7 \pm 0.6$ & $3.2 \pm 0.3$ \\
\hline $\operatorname{WBC}\left(10^{3} / \mu \mathrm{L}\right)$ & $8.79 \pm 3.59$ & $7.98 \pm 3.17$ & $10.39 \pm 1.90$ & $8.02 \pm 1.76$ & $9.05 \pm 4.60$ & $7.80 \pm 2.37$ \\
\hline Neutrophils (\%) & $18.1 \pm 6.6$ & $19.1 \pm 6.3$ & $16.4 \pm 4.0$ & $15.9 \pm 3.3$ & $20.2 \pm 4.7$ & $20.9 \pm 5.2$ \\
\hline Lymphocytes (\%) & $77.9 \pm 7.0$ & $77.2 \pm 6.1$ & $79.5 \pm 3.8$ & $79.9 \pm 3.1$ & $75.7 \pm 4.3$ & $74.7 \pm 5.9$ \\
\hline Monocytes (\%) & $2.1 \pm 0.7$ & $1.9 \pm 0.4$ & $1.9 \pm 0.3$ & $2.3 \pm 0.9$ & $2.0 \pm 0.4$ & $2.3 \pm 1.1$ \\
\hline Eosinophils (\%) & $0.7 \pm 0.2$ & $0.6 \pm 0.2$ & $0.7 \pm 0.2$ & $0.7 \pm 0.3$ & $1.1 \pm 0.7$ & $0.8 \pm 0.1$ \\
\hline Basophils (\%) & $0.2 \pm 0.1$ & $0.2 \pm 0.1$ & $0.2 \pm 0.1$ & $0.2 \pm 0.1$ & $0.2 \pm 0.1$ & $0.2 \pm 0.1$ \\
\hline PT (second) & $17.3 \pm 0.6$ & $17.3 \pm 0.7$ & $17.3 \pm 0.7$ & $17.6 \pm 0.8$ & $16.7 \pm 1.0$ & $16.1 \pm 0.7$ \\
\hline APTT (second) & $15.1 \pm 0.8$ & $14.4 \pm 2.0$ & $14.4 \pm 0.9$ & $14.3 \pm 1.0$ & $13.5 \pm 3.3$ & $11.2 \pm 2.6$ \\
\hline No. of animals & 10 & 9 & 10 & 10 & 5 & 5 \\
\hline \multicolumn{7}{|l|}{ Female } \\
\hline $\mathrm{RBC}\left(10^{6} / \mu \mathrm{L}\right)$ & $7.32 \pm 0.37$ & $7.20 \pm 0.29$ & $7.31 \pm 0.36$ & $7.07 \pm 0.26$ & $7.54 \pm 0.21$ & $7.75 \pm 0.33$ \\
\hline Hemoglobin (g/dL) & $14.4 \pm 0.6$ & $14.0 \pm 0.5$ & $14.1 \pm 0.5$ & $13.5 \pm 0.3^{* *}$ & $14.2 \pm 0.4$ & $14.1 \pm 0.5$ \\
\hline Hematocrit (\%) & $42.2 \pm 2.0$ & $41.1 \pm 1.8$ & $41.7 \pm 1.6$ & $40.0 \pm 1.2^{*}$ & $41.7 \pm 1.2$ & $42.0 \pm 1.5$ \\
\hline $\mathrm{MCV}(\mathrm{fL})$ & $57.7 \pm 1.5$ & $57.0 \pm 1.1$ & $57.1 \pm 1.9$ & $56.6 \pm 1.7$ & $55.3 \pm 2.3$ & $54.2 \pm 0.9$ \\
\hline $\mathrm{MCH}(\mathrm{pg})$ & $19.8 \pm 0.4$ & $19.5 \pm 0.4$ & $19.4 \pm 0.6$ & $19.2 \pm 0.6$ & $18.9 \pm 0.5$ & $18.3 \pm 0.3^{*}$ \\
\hline $\mathrm{MCHC}(\mathrm{g} / \mu \mathrm{L})$ & $34.2 \pm 0.5$ & $34.2 \pm 0.8$ & $33.9 \pm 0.3$ & $33.9 \pm 0.4$ & $34.2 \pm 1.0$ & $33.7 \pm 0.3$ \\
\hline Platelet $\left(10^{3} / \mu \mathrm{L}\right)$ & $1174 \pm 170$ & $1179 \pm 142$ & $1140 \pm 148$ & $1128 \pm 138$ & $1068 \pm 119$ & $1094 \pm 98$ \\
\hline Reticulocyte (\%) & $2.6 \pm 2.1$ & $2.5 \pm 1.4$ & $1.8 \pm 0.5$ & $2.5 \pm 1.3$ & $2.2 \pm 0.7$ & $1.5 \pm 0.3$ \\
\hline $\operatorname{WBC}\left(10^{3} / \mu \mathrm{L}\right)$ & $4.10 \pm 1.01$ & $4.37 \pm 1.39$ & $4.33 \pm 1.03$ & $5.17 \pm 2.19$ & $6.22 \pm 1.81$ & $4.54 \pm 1.19$ \\
\hline Neutrophils (\%) & $17.6 \pm 6.9$ & $14.4 \pm 6.5$ & $15.1 \pm 5.0$ & $20.4 \pm 6.0$ & $15.1 \pm 6.5$ & $14.7 \pm 4.1$ \\
\hline Lymphocytes (\%) & $79.2 \pm 7.2$ & $82.1 \pm 7.1$ & $81.2 \pm 5.2$ & $75.9 \pm 6.0$ & $81.1 \pm 7.7$ & $81.1 \pm 4.9$ \\
\hline Monocytes (\%) & $1.5 \pm 0.4$ & $1.9 \pm 0.8$ & $1.9 \pm 0.7$ & $2.1 \pm 0.7$ & $2.0 \pm 1.3$ & $2.0 \pm 0.6$ \\
\hline Eosinophils (\%) & $1.0 \pm 0.4$ & $0.8 \pm 0.3$ & $0.9 \pm 0.3$ & $0.9 \pm 0.4$ & $0.9 \pm 0.4$ & $1.1 \pm 0.4$ \\
\hline Basophils (\%) & $0.2 \pm 0.1$ & $0.1 \pm 0.1$ & $0.1 \pm 0.0$ & $0.1 \pm 0.0$ & $0.2 \pm 0.1$ & $0.2 \pm 0.1$ \\
\hline PT (second) & $18.5 \pm 0.6$ & $18.3 \pm 0.6$ & $18.1 \pm 0.6$ & $17.9 \pm 0.8$ & $18.9 \pm 0.5$ & $18.8 \pm 0.9$ \\
\hline APTT (second) & $14.2 \pm 0.8$ & $13.6 \pm 0.7$ & $13.9 \pm 1.1$ & $13.5 \pm 1.1$ & $13.9 \pm 0.8$ & $13.7 \pm 1.1$ \\
\hline No. of animals & 10 & 10 & 10 & 10 & 5 & 5 \\
\hline
\end{tabular}

RBC: red blood cell count, MCV: mean corpuscular volume, $\mathrm{MCH}$ : mean corpuscular hemoglobin, MCHC: mean corpuscular hemoglobin concentration, WBC: white blood cell count, PT: prothrombin time, APTT: active partial thromboplastin time.

Significantly different from vehicle control: ${ }^{*} p<0.05,{ }^{* *} p<0.01$. Values are mean \pm S.D.

were not considered toxicologically significant (28).

The increases in the relative weight of the kidneys of the male rats in the 100 and $400 \mathrm{mg} / \mathrm{kg} /$ day LEH-treated groups were statistically significant compared with those of the control group. In addition, the absolute and relative weights of the kidneys of the female rats in the $25 \mathrm{mg} / \mathrm{kg} / \mathrm{day}$ and higher dose LEH-treated groups showed smaller changes in the biological variation range than those observed in the control group. There were no abnormal changes in the hematological and serum biochemical examinations and morphological changes were not observed. Therefore, we determined that these findings had no toxicological significance.

The statistically significant changes observed in the other main study and recovery groups were not dose-dependent compared to the changes observed in the control group. In addition, they were not associated with the weight change after fasting, and no morphological changes were discovered in the organs. Therefore, there was no toxicological significance.

Histopathological examination: The results of the histopathological examination are shown in Table 5. There were histopathological changes in the kidney and stomach that were dose-related in the LEH-treated main study group. The results of the histopathological examination revealed the presence of red-brown pigmentation in the renal tubules of the male and female rats in the $100 \mathrm{mg} / \mathrm{kg} /$ day and higher 
Table 3. Serum biochemical values of male and female rats

\begin{tabular}{|c|c|c|c|c|c|c|}
\hline \multirow{2}{*}{ Items } & \multicolumn{4}{|c|}{ Main group (mg/kg/day) } & \multicolumn{2}{|c|}{ Recovery group (mg/kg/day) } \\
\hline & 0 & 25 & 100 & 400 & 0 & 400 \\
\hline \multicolumn{7}{|l|}{ Male } \\
\hline ALT (IU/L) & $27.1 \pm 2.8$ & $23.5 \pm 2.3$ & $23.6 \pm 4.8$ & $25.1 \pm 4.6$ & $34.1 \pm 10.4$ & $28.8 \pm 6.4$ \\
\hline AST (IU/L) & $65.5 \pm 9.8$ & $64.3 \pm 8.2$ & $64.5 \pm 6.5$ & $57.9 \pm 6.1$ & $101.2 \pm 20.0$ & $82.0 \pm 14.7$ \\
\hline ALP (IU/L) & $613.5 \pm 92.0$ & $522.5 \pm 109.7$ & $557.5 \pm 95.0$ & $477.9 \pm 74.2^{* *}$ & $403.7 \pm 95.3$ & $492.3 \pm 150.3$ \\
\hline GGT (IU/L) & $0.38 \pm 0.10$ & $0.39 \pm 0.14$ & $0.40 \pm 0.16$ & $0.37 \pm 0.17$ & $0.39 \pm 0.26$ & $0.31 \pm 0.23$ \\
\hline Glucose (mg/dL) & $159 \pm 18$ & $143 \pm 17$ & $150 \pm 18$ & $138 \pm 12^{*}$ & $147 \pm 15$ & $136 \pm 8$ \\
\hline BUN (mg/dL) & $11.8 \pm 1.4$ & $11.5 \pm 1.1$ & $12.9 \pm 2.3$ & $12.1 \pm 2.1$ & $13.6 \pm 1.8$ & $14.3 \pm 1.0$ \\
\hline Creatinine (mg/dL) & $0.41 \pm 0.02$ & $0.38 \pm 0.03$ & $0.40 \pm 0.03$ & $0.40 \pm 0.03$ & $0.45 \pm 0.02$ & $0.42 \pm 0.04$ \\
\hline TBil (mg/dL) & $0.04 \pm 0.01$ & $0.04 \pm 0.01$ & $0.05 \pm 0.01$ & $0.08 \pm 0.02^{* *}$ & $0.06 \pm 0.01$ & $0.05 \pm 0.01$ \\
\hline TCho (mg/dL) & $76 \pm 15$ & $70 \pm 15$ & $64 \pm 12$ & $73 \pm 11$ & $83 \pm 15$ & $77 \pm 16$ \\
\hline Triglyceride (mg/dL) & $36 \pm 12$ & $35 \pm 8$ & $36 \pm 18$ & $27 \pm 18$ & $51 \pm 33$ & $47 \pm 21$ \\
\hline $\mathrm{TP}(\mathrm{g} / \mathrm{dL})$ & $5.6 \pm 0.3$ & $5.5 \pm 0.2$ & $5.5 \pm 0.2$ & $5.6 \pm 0.3$ & $6.0 \pm 0.3$ & $5.6 \pm 0.2$ \\
\hline Albumin (g/dL) & $2.3 \pm 0.1$ & $2.3 \pm 0.1$ & $2.3 \pm 0.1$ & $2.5 \pm 0.1^{*}$ & $2.4 \pm 0.2$ & $2.4 \pm 0.1$ \\
\hline $\mathrm{A} / \mathrm{G}$ (ratio) & $0.72 \pm 0.04$ & $0.73 \pm 0.04$ & $0.73 \pm 0.04$ & $0.77 \pm 0.05^{*}$ & $0.69 \pm 0.03$ & $0.73 \pm 0.02^{*}$ \\
\hline $\mathrm{IP}(\mathrm{mg} / \mathrm{dL})$ & $7.30 \pm 0.61$ & $7.56 \pm 0.62$ & $9.09 \pm 0.77^{* *}$ & $10.66 \pm 0.83^{* *}$ & $6.54 \pm 0.53$ & $6.72 \pm 0.23$ \\
\hline $\mathrm{Ca}++(\mathrm{mg} / \mathrm{dL})$ & $9.9 \pm 0.3$ & $9.9 \pm 0.3$ & $9.9 \pm 0.3$ & $10.1 \pm 0.3$ & $10.1 \pm 0.2$ & $9.8 \pm 0.1$ \\
\hline $\mathrm{Na}+(\mathrm{mmol} / \mathrm{L})$ & $141 \pm 1$ & $141 \pm 1$ & $140 \pm 2$ & $140 \pm 3$ & $141 \pm 1$ & $141 \pm 1$ \\
\hline $\mathrm{K}+(\mathrm{mmol} / \mathrm{L})$ & $4.3 \pm 0.2$ & $4.6 \pm 0.2$ & $4.7 \pm 0.2^{* *}$ & $4.4 \pm 0.2$ & $4.5 \pm 0.3$ & $4.6 \pm 0.3$ \\
\hline $\mathrm{Cl}-(\mathrm{mmol} / \mathrm{L})$ & $103 \pm 1$ & $102 \pm 1$ & $101 \pm 2^{*}$ & $100 \pm 3^{*}$ & $105 \pm 2$ & $105 \pm 1$ \\
\hline No. of animals & 10 & 9 & 10 & 10 & 5 & 5 \\
\hline \multicolumn{7}{|l|}{ Female } \\
\hline ALT (IU/L) & $25.1 \pm 5.8$ & $23.2 \pm 5.0$ & $22.9 \pm 7.1$ & $26.6 \pm 5.4$ & $30.7 \pm 13.6$ & $24.3 \pm 6.1$ \\
\hline AST (IU/L) & $70.2 \pm 12.6$ & $70.8 \pm 20.8$ & $70.2 \pm 16.5$ & $71.6 \pm 12.0$ & $78.2 \pm 11.7$ & $71.0 \pm 9.3$ \\
\hline ALP (IU/L) & $323.6 \pm 71.2$ & $358.8 \pm 66.6$ & $341.3 \pm 81.9$ & $343.4 \pm 64.9$ & $250.2 \pm 63.7$ & $257.5 \pm 23.3$ \\
\hline GGT (IU/L) & $0.47 \pm 0.11$ & $0.64 \pm 0.20$ & $0.50 \pm 0.15$ & $0.58 \pm 0.17$ & $0.90 \pm 0.26$ & $0.72 \pm 0.15$ \\
\hline Glucose (mg/dL) & $127 \pm 14$ & $130 \pm 19$ & $119 \pm 14$ & $118 \pm 16$ & $143 \pm 11$ & $146 \pm 11$ \\
\hline BUN (mg/dL) & $12.2 \pm 1.7$ & $12.8 \pm 2.2$ & $12.8 \pm 2.4$ & $12.3 \pm 2.0$ & $14.4 \pm 1.7$ & $14.0 \pm 2.0$ \\
\hline Creatinine $(\mathrm{mg} / \mathrm{dL})$ & $0.44 \pm 0.02$ & $0.44 \pm 0.03$ & $0.41 \pm 0.02$ & $0.43 \pm 0.04$ & $0.50 \pm 0.04$ & $0.47 \pm 0.03$ \\
\hline TBil $(\mathrm{mg} / \mathrm{dL})$ & $0.06 \pm 0.02$ & $0.06 \pm 0.03$ & $0.06 \pm 0.02$ & $0.07 \pm 0.02$ & $0.09 \pm 0.02$ & $0.09 \pm 0.02$ \\
\hline TCho (mg/dL) & $72 \pm 9$ & $81 \pm 10$ & $80 \pm 11$ & $84 \pm 14$ & $84 \pm 14$ & $85 \pm 12$ \\
\hline Triglyceride (mg/dL) & $14 \pm 4$ & $17 \pm 6$ & $16 \pm 6$ & $15 \pm 5$ & $24 \pm 23$ & $21 \pm 16$ \\
\hline $\mathrm{TP}(\mathrm{g} / \mathrm{dL})$ & $5.7 \pm 0.3$ & $5.8 \pm 0.4$ & $5.7 \pm 0.4$ & $5.7 \pm 0.2$ & $6.1 \pm 0.3$ & $5.8 \pm 0.3$ \\
\hline Albumin (g/dL) & $2.6 \pm 0.1$ & $2.6 \pm 0.2$ & $2.6 \pm 0.2$ & $2.6 \pm 0.1$ & $2.6 \pm 0.1$ & $2.5 \pm 0.1$ \\
\hline $\mathrm{A} / \mathrm{G}$ (ratio) & $0.85 \pm 0.04$ & $0.80 \pm 0.04^{*}$ & $0.81 \pm 0.02^{*}$ & $0.85 \pm 0.06$ & $0.76 \pm 0.04$ & $0.77 \pm 0.05$ \\
\hline $\mathrm{IP}(\mathrm{mg} / \mathrm{dL})$ & $6.06 \pm 0.68$ & $6.47 \pm 0.66$ & $7.25 \pm 0.72^{* *}$ & $8.69 \pm 0.88^{* * *}$ & $4.97 \pm 0.24$ & $5.38 \pm 0.69$ \\
\hline $\mathrm{Ca}++(\mathrm{mg} / \mathrm{dL})$ & $9.9 \pm 0.2$ & $10.0 \pm 0.4$ & $10.1 \pm 0.3$ & $9.9 \pm 0.2$ & $9.5 \pm 0.4$ & $9.7 \pm 0.2$ \\
\hline $\mathrm{Na}+(\mathrm{mmol} / \mathrm{L})$ & $140 \pm 1$ & $138 \pm 1^{*}$ & $139 \pm 1$ & $138 \pm 2^{*}$ & $141 \pm 1$ & $140 \pm 1$ \\
\hline $\mathrm{K}+(\mathrm{mmol} / \mathrm{L})$ & $4.3 \pm 0.2$ & $4.5 \pm 0.4$ & $4.6 \pm 0.3$ & $4.3 \pm 0.2$ & $4.3 \pm 0.3$ & $4.3 \pm 0.3$ \\
\hline $\mathrm{Cl}-(\mathrm{mmol} / \mathrm{L})$ & $104 \pm 1$ & $103 \pm 1^{*}$ & $103 \pm 1^{*}$ & $102 \pm 2^{* *}$ & $107 \pm 1$ & $106 \pm 1$ \\
\hline No. of animals & 10 & 10 & 10 & 10 & 5 & 5 \\
\hline
\end{tabular}

ALT: alanine aminotransferase, AST: aspartate aminotransferase, ALP: alkaline phosphatase, GGT: gamma glutamyl transpeptidase, BUN: blood urea nitrogen, TBil: total bilirubin, TCho: total cholesterol, TP: total protein, A/G: albumin/globulin, IP: inorganic phosphorus. Significantly different from vehicle control: ${ }^{*} p<0.05,{ }^{* *} p<0.01$. Values are mean \pm S.D.

dose LEH-treated main groups. This pigmentation coincided with dark red discoloration of the kidneys observed during the necropsy and the changes in urine color. Consequently, it was considered a LEH-related change. The redbrown pigment in the renal tubules was possibly associated with hemosiderin, lipofuscin, or bilirubin, but no abnormal changes related to the function of the kidneys were observed in the hematological and serum biochemical examinations. In addition, morphological changes such as cell degenera- tion were not discovered during the histopathological examination. Therefore, it was suggested that the pigmentation was likely caused by LEH and it was not considered to be a toxicologically significant change.

The increase in the hyaline droplets observed in the renal tubules of the renal cortex of the male rats in the 100 and $400 \mathrm{mg} / \mathrm{kg}$ /day LEH-treated groups was observed only in the proximal tubule. Since a positive response was obtained in the $\mathrm{CAB}$ stain, it was likely to be $\alpha 2 \mathrm{u}$-globulin. Alterna- 
Table 4. Absolute and relative organ weights of male and female rats

\begin{tabular}{|c|c|c|c|c|c|c|}
\hline \multirow{2}{*}{ Items } & \multicolumn{4}{|c|}{ Main group (mg/kg/day) } & \multicolumn{2}{|c|}{ Recovery group (mg/kg/day) } \\
\hline & 0 & 25 & 100 & 400 & 0 & 400 \\
\hline \multicolumn{7}{|l|}{ Male } \\
\hline Body weight $^{\mathrm{a}}$ (g) & $375.9 \pm 21.7$ & $368.1 \pm 36.5$ & $374.4 \pm 27.4$ & $339.4 \pm 25.9^{*}$ & $453.1 \pm 22.3$ & $410.1 \pm 25.8^{*}$ \\
\hline Brain (g) & $2.02 \pm 0.08$ & $1.97 \pm 0.13$ & $1.97 \pm 0.10$ & $1.97 \pm 0.06$ & $2.02 \pm 0.16$ & $2.04 \pm 0.06$ \\
\hline$\%$ to body weight & $0.54 \pm 0.03$ & $0.54 \pm 0.04$ & $0.53 \pm 0.04$ & $0.58 \pm 0.05^{*}$ & $0.44 \pm 0.03$ & $0.50 \pm 0.04^{*}$ \\
\hline Pituitary (g) & $0.0113 \pm 0.0012$ & $0.0101 \pm 0.0027$ & $0.0111 \pm 0.0015$ & $0.0100 \pm 0.0012$ & $0.0106 \pm 0.0011$ & $0.0118 \pm 0.0012$ \\
\hline$\%$ to body weight & $0.0030 \pm 0.0002$ & $0.0027 \pm 0.0006$ & $0.0030 \pm 0.0003$ & $0.0029 \pm 0.0003$ & $0.0024 \pm 0.0003$ & $0.0029 \pm 0.0003^{*}$ \\
\hline Heart (g) & $1.26 \pm 0.12$ & $1.20 \pm 0.10$ & $1.25 \pm 0.08$ & $1.12 \pm 0.08^{* *}$ & $1.34 \pm 0.06$ & $1.24 \pm 0.11$ \\
\hline$\%$ to body weight & $0.34 \pm 0.03$ & $0.33 \pm 0.03$ & $0.33 \pm 0.02$ & $0.33 \pm 0.01$ & $0.30 \pm 0.02$ & $0.31 \pm 0.01$ \\
\hline Lungs (g) & $1.45 \pm 0.13$ & $1.39 \pm 0.09$ & $1.44 \pm 0.10$ & $1.38 \pm 0.07$ & $1.55 \pm 0.04$ & $1.45 \pm 0.14$ \\
\hline$\%$ to body weight & $0.39 \pm 0.02$ & $0.38 \pm 0.02$ & $0.39 \pm 0.02$ & $0.41 \pm 0.02$ & $0.35 \pm 0.02$ & $0.35 \pm 0.04$ \\
\hline Liver (g) & $11.85 \pm 1.62$ & $11.50 \pm 1.34$ & $12.75 \pm 1.55$ & $12.27 \pm 1.91$ & $13.76 \pm 1.61$ & $12.20 \pm 1.25$ \\
\hline$\%$ to body weight & $3.15 \pm 0.33$ & $3.12 \pm 0.19$ & $3.40 \pm 0.20$ & $3.60 \pm 0.30^{* * *}$ & $3.03 \pm 0.27$ & $2.97 \pm 0.17$ \\
\hline Spleen $(\mathrm{g})$ & $0.77 \pm 0.15$ & $0.67 \pm 0.11$ & $0.71 \pm 0.11$ & $0.62 \pm 0.08^{*}$ & $0.86 \pm 0.28$ & $0.77 \pm 0.18$ \\
\hline$\%$ to body weight & $0.20 \pm 0.04$ & $0.18 \pm 0.02$ & $0.19 \pm 0.04$ & $0.18 \pm 0.03$ & $0.19 \pm 0.06$ & $0.19 \pm 0.04$ \\
\hline Kidneys (g) & $2.81 \pm 0.28$ & $2.79 \pm 0.31$ & $2.98 \pm 0.23$ & $2.82 \pm 0.34$ & $2.99 \pm 0.17$ & $3.01 \pm 0.26$ \\
\hline$\%$ to body weight & $0.75 \pm 0.04$ & $0.76 \pm 0.05$ & $0.80 \pm 0.03^{*}$ & $0.83 \pm 0.06^{* *}$ & $0.66 \pm 0.02$ & $0.73 \pm 0.03^{* *}$ \\
\hline Adrenals (g) & $0.0600 \pm 0.0090$ & $0.0597 \pm 0.0083$ & $0.0609 \pm 0.0112$ & $0.0675 \pm 0.0069$ & $0.0668 \pm 0.0087$ & $0.0622 \pm 0.0107$ \\
\hline$\%$ to body weight & $0.0160 \pm 0.0021$ & $0.0162 \pm 0.0015$ & $0.0162 \pm 0.0022$ & $0.0200 \pm 0.0024^{* *}$ & $0.0148 \pm 0.0018$ & $0.0152 \pm 0.0026$ \\
\hline Testes (g) & $3.26 \pm 0.33$ & $3.30 \pm 0.21$ & $3.38 \pm 0.31$ & $3.23 \pm 0.13$ & $3.35 \pm 0.13$ & $3.41 \pm 0.18$ \\
\hline$\%$ to body weight & $0.87 \pm 0.08$ & $0.90 \pm 0.07$ & $0.90 \pm 0.07$ & $0.95 \pm 0.06$ & $0.74 \pm 0.06$ & $0.84 \pm 0.08$ \\
\hline Prostate gland (g) & $0.50 \pm 0.10$ & $0.47 \pm 0.10$ & $0.51 \pm 0.14$ & $0.38 \pm 0.12$ & $0.55 \pm 0.08$ & $0.54 \pm 0.08$ \\
\hline$\%$ to body weight & $0.13 \pm 0.02$ & $0.13 \pm 0.03$ & $0.14 \pm 0.03$ & $0.11 \pm 0.04$ & $0.12 \pm 0.02$ & $0.13 \pm 0.02$ \\
\hline No. of animals & 10 & 9 & 10 & 10 & 5 & 5 \\
\hline \multicolumn{7}{|l|}{ Female } \\
\hline Body weight $^{\mathrm{a})}$ (g) & $213.7 \pm 16.1$ & $231.7 \pm 7.6$ & $219.0 \pm 21.3$ & $221.7 \pm 17.0$ & $239.8 \pm 25.2$ & $246.7 \pm 25.0$ \\
\hline Brain $(g)$ & $1.87 \pm 0.06$ & $1.85 \pm 0.06$ & $1.81 \pm 0.08$ & $1.82 \pm 0.09$ & $1.87 \pm 0.12$ & $1.88 \pm 0.09$ \\
\hline$\%$ to body weight & $0.88 \pm 0.08$ & $0.80 \pm 0.03$ & $0.84 \pm 0.11$ & $0.83 \pm 0.08$ & $0.78 \pm 0.07$ & $0.77 \pm 0.12$ \\
\hline Pituitary (g) & $0.0128 \pm 0.0013$ & $0.0135 \pm 0.0018$ & $0.0128 \pm 0.0017$ & $0.0139 \pm 0.0013$ & $0.0128 \pm 0.0031$ & $0.0151 \pm 0.0024$ \\
\hline$\%$ to body weight & $0.0060 \pm 0.0006$ & $0.0058 \pm 0.0008$ & $0.0059 \pm 0.0009$ & $0.0063 \pm 0.0004$ & $0.0053 \pm 0.0010$ & $0.0061 \pm 0.0006$ \\
\hline Heart $(\mathrm{g})$ & $0.76 \pm 0.07$ & $0.82 \pm 0.05$ & $0.75 \pm 0.10$ & $0.80 \pm 0.06$ & $0.79 \pm 0.09$ & $0.86 \pm 0.10$ \\
\hline$\%$ to body weight & $0.36 \pm 0.01$ & $0.36 \pm 0.01$ & $0.34 \pm 0.03$ & $0.36 \pm 0.02$ & $0.33 \pm 0.02$ & $0.35 \pm 0.03$ \\
\hline Lungs (g) & $1.06 \pm 0.07$ & $1.09 \pm 0.06$ & $1.10 \pm 0.15$ & $1.27 \pm 0.11^{* *}$ & $1.09 \pm 0.12$ & $1.13 \pm 0.07$ \\
\hline$\%$ to body weight & $0.49 \pm 0.03$ & $0.47 \pm 0.02$ & $0.50 \pm 0.04$ & $0.57 \pm 0.06^{*}$ & $0.45 \pm 0.02$ & $0.46 \pm 0.03$ \\
\hline Liver $(\mathrm{g})$ & $6.35 \pm 0.66$ & $7.15 \pm 0.47$ & $6.84 \pm 1.05$ & $8.05 \pm 0.70^{* *}$ & $6.67 \pm 0.98$ & $7.08 \pm 1.17$ \\
\hline$\%$ to body weight & $2.97 \pm 0.14$ & $3.09 \pm 0.19$ & $3.11 \pm 0.25$ & $3.64 \pm 0.26^{* *}$ & $2.77 \pm 0.16$ & $2.85 \pm 0.25$ \\
\hline Spleen (g) & $0.52 \pm 0.14$ & $0.51 \pm 0.10$ & $0.48 \pm 0.07$ & $0.52 \pm 0.15$ & $0.57 \pm 0.07$ & $0.51 \pm 0.04$ \\
\hline$\%$ to body weight & $0.24 \pm 0.07$ & $0.22 \pm 0.05$ & $0.22 \pm 0.04$ & $0.23 \pm 0.06$ & $0.24 \pm 0.04$ & $0.21 \pm 0.01$ \\
\hline Kidneys (g) & $1.58 \pm 0.08$ & $1.77 \pm 0.12^{* *}$ & $1.71 \pm 0.14$ & $1.83 \pm 0.16^{* *}$ & $1.62 \pm 0.16$ & $1.73 \pm 0.18$ \\
\hline$\%$ to body weight & $0.74 \pm 0.04$ & $0.76 \pm 0.04$ & $0.78 \pm 0.06$ & $0.83 \pm 0.07^{* *}$ & $0.68 \pm 0.05$ & $0.71 \pm 0.05$ \\
\hline Adrenals (g) & $0.0681 \pm 0.0069$ & $0.0686 \pm 0.0119$ & $0.0679 \pm 0.0049$ & $0.0740 \pm 0.0067$ & $0.0690 \pm 0.0100$ & $0.0772 \pm 0.0092$ \\
\hline$\%$ to body weight & $0.0320 \pm 0.0039$ & $0.0297 \pm 0.0055$ & $0.0311 \pm 0.0021$ & $0.0336 \pm 0.0046$ & $0.0288 \pm 0.0033$ & $0.0313 \pm 0.0027$ \\
\hline Ovary $(\mathrm{g})$ & $0.0877 \pm 0.0093$ & $0.0911 \pm 0.0100$ & $0.0827 \pm 0.0150$ & $0.0935 \pm 0.0123$ & $0.0821 \pm 0.0134$ & $0.0865 \pm 0.0112$ \\
\hline$\%$ to body weight & $0.0411 \pm 0.0044$ & $0.0394 \pm 0.0045$ & $0.0379 \pm 0.0069$ & $0.0422 \pm 0.0054$ & $0.0342 \pm 0.0036$ & $0.0353 \pm 0.0053$ \\
\hline Uterus (g) & $0.47 \pm 0.18$ & $0.47 \pm 0.11$ & $0.53 \pm 0.23$ & $0.53 \pm 0.20$ & $0.64 \pm 0.18$ & $0.68 \pm 0.24$ \\
\hline$\%$ to body weight & $0.22 \pm 0.09$ & $0.20 \pm 0.05$ & $0.24 \pm 0.09$ & $0.24 \pm 0.10$ & $0.27 \pm 0.09$ & $0.28 \pm 0.08$ \\
\hline No. of animals & 10 & 10 & 10 & 10 & 5 & 5 \\
\hline
\end{tabular}

${ }^{a}$ The body weights were measured right before necropsy after overnight fasting.

Significantly different from vehicle control: ${ }^{*} p<0.05,{ }^{* *} p<0.01$. Values are mean \pm S.D.

tively, $\alpha 2 \mathrm{u}$-globulin is known to be observed only in male rats and to have little relevance in humans $(29,30)$. The change was observed even after the 2-week recovery period, but the degree and frequency were lower than those observed in the main groups and it was considered partially recovered.

In the forestomach, there appeared to be a minimal to mild irritation, thickening, erosion, and inflammatory cell 
Table 5. Incidence and severity of test substance-related microscopic findings of male and female rats

\begin{tabular}{|c|c|c|c|c|c|c|c|c|c|c|c|c|c|}
\hline \multirow{3}{*}{ Parameters } & & \multicolumn{6}{|c|}{ Male } & \multicolumn{6}{|c|}{ Female } \\
\hline & & \multicolumn{4}{|c|}{$\begin{array}{l}\text { Main group } \\
(\mathrm{mg} / \mathrm{kg} / \text { day })\end{array}$} & \multicolumn{2}{|c|}{$\begin{array}{l}\text { Recovery group } \\
(\mathrm{mg} / \mathrm{kg} / \text { day })\end{array}$} & \multicolumn{4}{|c|}{$\begin{array}{l}\text { Main group } \\
(\mathrm{mg} / \mathrm{kg} / \text { day })\end{array}$} & \multicolumn{2}{|c|}{$\begin{array}{c}\text { Recovery group } \\
(\mathrm{mg} / \mathrm{kg} / \text { day })\end{array}$} \\
\hline & & 0 & 25 & 100 & 400 & 0 & 400 & 0 & 25 & 100 & 400 & 0 & 400 \\
\hline \multicolumn{14}{|l|}{ Kidney } \\
\hline $\begin{array}{l}\text { - Increased, hyaline droplets, } \\
\text { tubular, cortex }\end{array}$ & \pm & 0 & 0 & 4 & 7 & 0 & 1 & 0 & 0 & 0 & 0 & 0 & 0 \\
\hline \multirow{3}{*}{$\begin{array}{l}\text { - Presence, red brown pigment, } \\
\text { tubular, cortex }\end{array}$} & \pm & 0 & 0 & 2 & 5 & 0 & 3 & 0 & 0 & 7 & 4 & 0 & 2 \\
\hline & + & 0 & 0 & 0 & 5 & 0 & 0 & 0 & 0 & 1 & 4 & 0 & 3 \\
\hline & ++ & 0 & 0 & 0 & 0 & 0 & 0 & 0 & 0 & 0 & 2 & 0 & 0 \\
\hline Total Number of affected & & 0 & 0 & 5 & 10 & 0 & 4 & 0 & 0 & 8 & 10 & 0 & 5 \\
\hline \multicolumn{14}{|l|}{ Stomach } \\
\hline - Erosion, forestomach & + & 0 & 0 & 0 & 1 & 0 & 0 & 0 & 0 & 0 & 0 & 0 & 0 \\
\hline $\begin{array}{l}\text { - Inflammatory cell infiltration, } \\
\text { submucosa, forestomach }\end{array}$ & \pm & 0 & 0 & 0 & 1 & 0 & 0 & 0 & 0 & 0 & 0 & 0 & 0 \\
\hline - Thickening, mucsoa, forestomach & \pm & 0 & 0 & 0 & 3 & 0 & 0 & 0 & 0 & 2 & 5 & 0 & 0 \\
\hline Total Number of affected & & 0 & 0 & 0 & 3 & 0 & 0 & 0 & 0 & 2 & 5 & 0 & 0 \\
\hline No. of examined & & 10 & 9 & 10 & 10 & 5 & 5 & 10 & 10 & 10 & 10 & 5 & 5 \\
\hline
\end{tabular}

Grade- \pm : minimal, +: mild, ++: moderate.

infiltration of the submucosa. However, the forestomach is present only in rodents, and no LEH-related changes were observed in the other digestive organs including the glandular stomach. Therefore, the toxicological significance was minimal.

The other findings observed in the male and female rats in the control groups and LEH-treated groups were not related to the treatment because there was no dose response, and also because of small magnitude of change, and low incidence. Moreover, other lesions, which are well known to occur spontaneously in SD rats of the same age, were observed.

According to the above results, the LEH-related changes observed in the clinical signs, urinalysis, serum biochemical examination, necropsy, and histopathological examination were caused by the inherent color of LEH and they were determined to be toxicologically insignificant.

In conclusion, no deaths occurred in the acute oral toxicity study. Therefore, the ALD of LEH was higher than $2,000 \mathrm{mg} / \mathrm{kg}$ in male and female rats. In the subacute toxicity study, there were no toxicologically significant changes in the clinical signs, body weight, food consumption, ophthalmoscopic examination, urinalysis, hematological and serum biochemical examinations, organ weights, necropsy, and histopathological examination of all the animals treated with LEH. These results suggest that the NOAEL of LEH is greater than $400 \mathrm{mg} / \mathrm{kg} /$ day in both sexes, and the target organs were not established.

\section{ACKNOWLEDGMENTS}

This research was supported by the Bio-industry Technol- ogy Development Program (Project No. 311054-3), of the Ministry of Agriculture, Food and Rural Affairs, Republic of Korea.

\section{REFERENCES}

1. World Health Organization. (2002) WHO traditional medicine strategy. WHO, Geneva, pp. 2002-2005.

2. Jakkula, M., Boucher, T.A., Beyendorff, U., Conn, S.M., Johnson, J.E., Nolan, C.J., Peine, C.J. and Albrecht, J.H. (2004) A randomized trial of Chinese herbal medicines for the treatment of symptomatic hepatitis C. Arch. Intern. Med., 164, 1341-1346.

3. Haller, C.A. and Benowitz, N.L. (2000) Adverse cardiovascular and central nervous system events associated with dietary supplements containing ephedra alkaloids. N. Engl. J. Med., 343, 1833-1838.

4. Palmer, M.E., Haller, C., McKinney, P.E., Klein-Schwartz, W., Tschirgi, A., Smolinske, S.C., Woolf, A., Sprague, B.M., Ko, R., Everson, G., Nelson, L.S., Dodd-Butera, T., Bartlett, W.D. and Landzberg, B.R. (2003) Adverse events associated with dietary supplements: an observational study. Lancet, 361, 101106.

5. Pittler, M.H. and Ernst, E. (2003) Systematic review: hepatotoxic events associated with herbal medicinal products. Aliment. Pharmacol. Ther., 18, 451-471.

6. Papageorgiou, V.P., Assimopoulou, A.N., Couladouros, E.A., Hepworth, D. and Nicolaou, K.C. (1999) The chemistry and biology of alkannin, shikonin, and related naphthazarin natural products. Angew. Chem. Int. Ed., 38, 270-301.

7. Papathanasiou, K., Papageorgiou, C., Panidis, D. and Mantalenakis, S. (1999) Our experience in laparoscopic diagnosis and management in women with chronic pelvic pain. Clin. 
Exp. Obstet. Gynecol., 26, 190-192.

8. Chen, X., Yang, L., Oppenheim, J.J. and Howard, M.Z. (2002) Cellular pharmacology studies of shikonin derivatives. Phytother. Res., 16, 199-209.

9. Choi, S.B., Bae, G.S., Jo, I.J., Park, K.C., Seo, S.H., Kim, D.G., Shin, J.Y., Gwak, T.S., Lee, J.H., Lee, G.S, Park, S.J. and Song, H.J. (2013) The anti-inflammatory effect of Lithospermum Erythrorhizon on lipopolysaccharide - induced inflammatory response in RAW 264.7 cells. Korea J. Herbology, 28, 67-73.

10. Chung, H.S., Kang, M., Cho, C., Park, S., Kim, H., Yoon, Y.S., Kang, J., Shin, M.K., Hong, M.C. and Bae, H. (2005) Inhibition of lipopolysaccharide and interferon-gammainduced expression of inducible nitric oxide synthase and tumor necrosis factor-alpha by Lithospermi radix in mouse peritoneal macrophages. J. Ethnopharmacol., 102, 412-417.

11. Han, K.Y., Kwon, T.H., Lee, T.H., Lee, S.J., Kim, S.H. and Kim, J. (2008) Suppressive effects of Lithospermum erythrorhizon extracts on lipopolysaccharide-induced activation of AP-1 and NFkappaB via mitogen-activated protein kinase pathways in mouse macrophage cells. BMB Rep., 41, 328333.

12. Jin, R., Wan, L.L., Mitsuishi, T., Kodama, K. and Kurashige, S. (1994) Immunomodulative effects of Chinese herbs in mice treated with anti-tumor agent cyclophosphamide. Yakugaku Zasshi, 114, 533-538.

13. Gong, K. and Li, W. (2011) Shikonin, a Chinese plant-derived naphthoquinone, induces apoptosis in hepatocellular carcinoma cells through reactive oxygen species: A potential new treatment for hepatocellular carcinoma. Free Radical Biol. Med., 51, 2259-2271.

14. Chen, X., Yang, L., Zhang, N., Turpin, J.A., Buckheit, R.W., Osterling, C., Oppenheim, J.J. and Howard, O.M. (2003) Shikonin, a component of chinese herbal medicine, inhibits chemokine receptor function and suppresses human immunodeficiency virus type 1. Antimicrob. Agents Chemother., 47, 2810-2816.

15. Pietrosiuk, A., Skopińska-Rózewska, E., Furmanowa, M., Wiedenfeld, H., Sommer, E., Sokolnicka, I., Rogala, E., Radomska-Leśniewska, D., Bany, J. and Malinowski, M. (2004) Immunomodulatory effect of shikonin derivatives isolated from Lithospermum canescens on cellular and humoral immunity in Balb/c mice. Pharmazie, 59, 640-642.

16. Kim, S.M., Cho, U.S. and Sung, S.K. (1999) Effect of ethanol extract in Pinus densiflora, Lithospermun erythrorhizon on the lipid oxidation oil emulsion. J. Korean Soc. Food Sci. Nutr., 28, 984-989.

17. Chung, H.S., Kang, M., Cho, C., Park, S., Kim, H., Yoon, Y.S., Kang, J., Shin, M.K., Hong, M.C. and Bae, H. (2005) Inhibition of lipopolysaccharide and interferon-gammainduced expression of inducible nitric oxide synthase and tumor necrosis factor-alpha by Lithospermi radix in mouse peritoneal macrophages. J. Ethnopharmacol., 102, 412-417.
18. Ju, J.H., Cho, H.H. and Lee, Y.S. (2010) Progress on phytochemical and atopic dermatitis-related study of the root of Lithospermum erythrorhizon. Korean J. Pharmacogn., 41, 7388.

19. Kim, S.H., Lee, J.Y. and Kim, D.K. (2005) Effects of mori folium, arctii fructus, Lithospermum Erythrorhizon on the anti-allergic response. J. Kyung Hee Univ. Med. Cent., 21, 7179.

20. Jeong, Y.S., Jung, H.K. and Hong, J.H. (2013) Protective effect of mulberry and Lithospermum erythrorhizon extracts on anti-aging against photodamage. J. Korean Soc. Food Sci. Nutr., 42, 1744-1752.

21. Ishida, T. and Sakaguchi, I. (2007) Protection of human keratinocytes from UVB-induced inflammation using root extract of Lithospermum erythrorhizon. Biol. Pharm. Bull., 30, 928934.

22. Lee, H.H. and Song, S.Y. (2010) A study of effectiveness of Lithospermum erythrorhizon extracts on the skin by UVBirradiation C57BL/6 mouse. Korean J. Microsc., 40, 139-145.

23. Park, Y.H. and Nam, Y.J. (2003) The antibacterial activity and deodorization of fabrics dyed with Lithospermi Radix extract. J. Korean Soc. Clothing Text., 27, 60-66.

24. Papageorgioua, V.P., Assimopoulou, A.N., Samanidou, V.F. and Papadoyannis, I.N. (2006) Recent advances in chemistry,biology and biotechnology of alkannins and shikonins. Curr. Org. Chem., 10, 2123-2142.

25. Bae, J.H. (2004) Antimicrobial effect of Lithospermum erythrorhizon extracts on the food-borne pathogens. Korean $J$. Food Sci. Technol., 36, 823-827.

26. Rajasekar, S., Park, D.J., Park, C., Park, S., Park, Y.H., Kim, S.T., Choi, Y.H. and Choi, Y.W. (2012) In vitro and in vivo anticancer effects of Lithospermum erythrorhizon extract on B16F10 murine melanoma. J. Ethnopharmacol., 144, 335345.

27. Lee, J.M., Lee, M.A., Do, H.N., Bae, R.J.N., Lee, M.J., Kim, M.J., Jang, H.S., Park, S.H., Lee, H.Y., Kang, J.S. and Kang, J.K. (2012) Historical control data from 4-week repeated toxicity studies in Crj:CD(SD) rats. J. Exp. Biomed. Sci., 18, 268275.

28. Hall, A.P., Elcombe, C.R., Foster, J.R., Harada, T., Kaufmann, W., Knippel, A., Kuttler, K., Malarkey, D.E., Maronpot, R.R., Nishikawa, A., Nolte, T., Schulte, A., Strauss, V. and York, M.J. (2012) Liver hypertrophy a review of adaptive (adverse and non-adverse) changes - conclusions from the 3rd international ESTP Expert Workshop. Toxicol. Pathol., 40, 971-994.

29. Olson, M.J., Johnson, J.T. and Reidy, C.A. (1990) A comparison of male rat and human urinary proteins: implications for human resistance to hyaline droplet nephropathy. Toxicol. Appl. Pharmacol., 102, 524-536.

30. Greaves, P. (2000) Histopathology of preclinical toxicity studies: interpretation and relevance in drug safety evaluation (2nd edition). Elsevier, Amsterdam, pp. 564-565. 